\title{
Implementasi Metode Super Resolusi Untuk Meningkatkan Kualitas Citra Hasil Screenshot
}

\author{
Windi Astuti \\ Prodi Teknik Informatika, STMIK Budi Darma, Medan, Indonesia \\ Email: windya741@gmail.com \\ Submitted 22-04-2020; Accepted 01-06-2020; Published 14-06-2020
}

\begin{abstract}
Abstrak
Berbagai jenis pengolahan citra yang dapat dilakukan oleh komputer, seperti meningkatkan kualitas citra merupakan salah satu bidang cukup popular hingga saat ini. Meningkatan kualitas suatu citra sangat diperlukan hingga agar seseorang dapat mengamati citra tersebut dengan jelas dan detail tanpa adanya ganguan. Suatu citra dapat mengalami gangguan atau kesalahan yang utama pada suatu citra misalnya citra hasil screenshot dijadikan sebagai sampel. Hasil citra dari screenshot memiliki tingkat ketajaman dan kehalusan citra yang terkecil, sehingga untuk mendapatkan citra yang lebih baik biasanya dilakukan pembesaran terhadap citra tersebut. Setelah hasil screenshot didapatkan maka, proses selanjutnya adalah mengcroping gambar tersebut dan gambar tampak terlihat ada gangguan seperti terlihat blur dan pecah-pecah. Untuk mendapatkan pembesaran citra (Zooming image) dengan cara penambahan piksel atau titik baru. Hal ini dilakukan dengan metode super resolusi, super resolusi mempunyai tiga tahap penyelesaiannya pertama Registrasi, Interpolasi, dan Rekontruksi. Untuk pembesaran dilakukan dengan interpolasi linier dan rekontruksi menggunakan median filter untuk penghalusan citra. Dengan metode ini diharapkan mampu menyelesaikan masalah meningkatkan kualitas citra pada aplikasi pembesaran citra. Penelitian ini membahas agar proses yang dilakukan untuk menerapkan pembesaran citra berdasarkan metode super resolusi maka, dibangun aplikasi dengan menggunakan matlab R2013a sebagai editor untuk mengedit program.
\end{abstract}

Kata Kunci: Citra Digital, Pembesaran, Super Resolusi, Matlab.

\begin{abstract}
Various types of image processing that can be done by computers, such as improving image quality is one of the fields that is quite popular until now. Improving the quality of an image is necessary so that someone can observe the image clearly and in detail without any disturbance. An image can experience major disturbances or errors in an image such as the image of the screenshot is used as a sample. The results of the image from the screenshot have the smallest sharpness and smoothness of the image, so to get a better image is usually done enlargement of the image. After the screenshot results are obtained then, the next process is cropping the image and the image looks like there are disturbances such as visible blur and cracked. To get an enlarged image (Zooming image) by adding new pixels or points. This is done by the super resolution method, super resolution has three stages of completion, first Registration, Interpolation, and Reconstruction. For magnification done by linear interpolation and reconstruction using a median filter for image refinement. This method is expected to be able to solve the problem of improving image quality in image enlargement applications. This study discusses that the process carried out to implement image enlargement based on the super resolution method is then built by using R2013a matlab as an editor to edit programs.
\end{abstract}

Keywords: Digital Image, Magnification, Super Resolution, Matlab.

\section{PENDAHULUAN}

Pengolahan citra merupakan bidang yang berkembang pesat dan banyak diterapkan pada ilmu-ilmu murni dan teknik. Proses diperolehnya citra ini dimulai dengan adanya sumber cahaya yang menerangi suatu objek. Pengolahan citra itu sendri adalah istilah umum untuk berbagai teknik yang keberadaannyauntuk memanipulasi dan memodifikasikan citra dengan berbagai cara. Tidak setiap kali citra yang didapatkan selalu sesuai dengan keinginan, atau dengan kadang kala citra yang didapatkan terlalu kecil dan beresolusi rendah. Pengolahan citra digital bagian penting yang mendasari bebagai aplikasi nyata,seperti pengenalan pola, pengendaraan jarak jauh melalui satelit atau pesawat udara, dan sangat berperan memisahkan objek yang akan diproses dan banyak peralatan elektronik yang dibutuhkan didalam citra digital misalnya, scanner kamera digital, mikroskop digital, dan fingerprint reader yang menghasilkan citra digital. Screenshot adalah suatu gambar tampilan yang diambil dari layar monitor seperti perangkat komputer, tablet PC, dan smartphone. Hasil citra dari screenshot memiliki tingkat ketajaman dan kehalusan citra yang terkecil, sehingga untuk mendapatkan citra yang lebih baik biasanya dilakukan pembesaran terhadap citra tersebut secara langsung, namun memiliki tingkat kecerahan yang kurang baik[1].

Dalam jurnal penelitian Soeb Aripin, Hery Sunandar pada tahun 2016 yang berjudul "perancangan aplikasi perbaikan citra pada hasil screenshot menggunakan metode interpolasi linier, perbaikan citra gambar screenshot dapat diperbaiki dengan salah satu metode perbaikan citra yaitu, interpolasi linier dimana hasil pembesaran citra dilakukan didalam objek bitmap dan resolusi akan bertambah setelah proses pembesaran dilakukan pada gambar masukan. setelah hasil penyeleksian hasil gambar screenshot di dapat proses selanjutnya membaca resolusi citra masukan yang berupa bitmap objek yang berguna untuk mengetahui ukuran/resolusi citra tersebut[2].

Agar screenshot yang kita ambil sempurna dan bagus, tentunya kita membutuhkan gambar resolusi tinggi, gambar dengan resolusi tinggi apabila dibesarkan gambar tidak akan terlihat blur atau pecah. Meningkatkan kecerahan citra pada perbaikan kualitas citra hasil screenshot memiliki gambar yang kaya, akan tetapi tidak semua citra hasil screenshot memiliki tampilan visual yang memuaskan mata manusia. Dalam hasil pembesaran tersebut, tentunya terdapat blur pada citra hasil screenshot, sehingga citra hasil screenshot akan tampak seperti kotak-kotak atau pecah. Hal ini terjadi karena proses pembesaran, menyusun citra hasil screenshot menjadi lebih kecil dan resolusi yang rendah[3]. 


\section{METODE PENELITIAN}

\subsection{Citra Digital}

Citra digital merupakan digital pemrosesan gambar 2 dimensi menggunakan komputer. Dalam konteks yang lebih luas, pengolahan citra digital mengacu pada pemrosesan setiap data 2 dimensi. Citra digital merupakan sebuah larik (array) yang berisi nilai-nilai real maupun komplek yang direpresentasikan dengan deretan bil tertentu[5].

\subsection{Resolusi Citra}

Resolusi citra merupakan tingkat detail suatu citra. Semakin tinggi resolusi citra maka akan semakin tinggi pula tingkat detail dari citra tersebut. Satuan dalam pengukuran resolusi citra dapat berupa ukuran fisik (jumlah garis per $\mathrm{mm} / \mathrm{jumlah}$ garis per inchi) ataupun dapat juga berupa ukuran citra menyeluruh (jumlah garis per tinggi citra)[5].

\subsection{Citra Hasil Screenshot}

Screenshot adalah suatu gambar tampilan layar yang diambil dari layar monitor seperti perangkat komputer, tablet PC, dan smartphone [3]. Screenshot biasa disebut SS merupakan sebuah gambar yang diambil melalui komputer atau lebih mudahnya adalah jepretan layar yang tampil pada monitor. Hasil citra dari screenshot memiliki tingkat ketajaman dan kehalusan citra yang kecil, tingkat kehaluasan dan ketajaman merupakan salah satu parameter yang utama dalam pemprosesan, sehingga untuk mendapatkan citra yang lebih baik biasanya dilakukan pembesaran (zooming) terhadap citra tersebut secara langsung namun memiliki tingkat kecerahan yang kurang baik.

\subsection{Metode Super Resolusi}

Teknik citra super resolusi adalah salah satu teknik untuk mendapatkan citra yang beresolusi tinggi dari sekumpulan citra yang beresolusi rendah. Resolusi tinggi yang dihasilkan dapat berupa citra tunggal atau lebih.

Super resolusi secara umum terdiri dari tiga tahap algoritma yaitu :

1. Registrasi

Registrasi citra adalah proses menemukannya kembali titik-titik yang bersesuaian antara citra $\mathrm{I}_{1}$ dengan $\mathrm{I}_{2}$ adalah citra $\mathrm{I}$ digeometri. Registrasi citra pada domain frame,lainya pada setiap nilai derajat keabuan (grayscale) atau RGB citra. Penelitian ini menggunakan registrasi average dan registrasi median.

a. Registrasi Average

Registrasi average adalah salah satu metode registrasi sederhana yang melakukan pencarian nilai rata-rata piksel dari beberapa frame citra yang mengalami transformasi geomatri, kemudian membaginya dengan banyaknya frame citra[2]. Persamaan pencarian nilai rata-rata piksel ditunjukkan pada persamaan

$$
\mathrm{f}(\mathrm{x}, \mathrm{y})=\frac{\mathrm{x}_{1}+\mathrm{x}_{2}+\mathrm{x}_{3}+\mathrm{x}_{4}+\mathrm{x}_{5}+\mathrm{x}_{6}+\mathrm{x}_{7}+\mathrm{x}_{8}+\mathrm{x}_{9}}{\mathrm{n}}
$$

b. Registrasi Median

Registrasi median adalah metode registrasi citra yang melakukan pencarian nilai piksel yang bersesuaian dengan

2. Interpolasi melakukan pengurutan terlebih dahulu. Pengurutan nilai dimulai dari nilai piksel terkecil hingga nilai piksel terbesar

Interpolasi (biasa disebut resampling) adalah sebuah metode penvitraan untuk meningkatkan (atau mengurangi) jumlah piksel dalam citra digital. Interpolasi citra bekerja dalam dua arah dan mencoba untuk mencapai pendekatan yang terbaik dari sebuah piksel yang warna dan intensitasnya didasarkan pada nilai-nilai di sekitar piksel. Penelitian ini menggunakan interpolasi bilinier dan bikubik untuk proses pembesaran (zooming) citra.

a. Interpolsi Billinier

Interpolasi billinier menentukan nilai piksel baru berdasarkan rata-rata (dengan memberi bobot) daro 4 piksel dari ukuran $2 \times 2$ piksel tetangga terdekat dalam gambar asli. Persamaan dari interpolasi billinier dapat dituliskan seperti persamaan (3).

$$
\begin{aligned}
f(x, y)= & \frac{f(C i i)}{\left(x_{2}-x_{1}\right)}\left(x_{2}-X\right)+\frac{f\left(Q_{11}\right)}{\left(x_{2}-x_{1}\right)\left(y_{2}-y_{1}\right)}\left(x_{2}-\mathrm{x}\right)\left(y_{2}-\mathrm{y}\right)+ \\
& \frac{f\left(Q_{21}\right)}{\left(x_{2}-x_{1}\right)\left(y_{2}-y_{1}\right)}\left(x_{2}-\mathrm{x}\right)\left(y_{2}-\mathrm{y}\right)+\frac{f\left(Q_{22}\right)}{\left(x_{2}-x_{1}\right)\left(y_{2}-y_{1}\right)\left(x_{2}-\mathrm{x}\right)\left(y_{2}-\mathrm{y}\right)}
\end{aligned}
$$

Keterangan

$\mathrm{f}=$ frekuensi kelas median

$\mathrm{x}=$ lokasi piksel baru horizontal

$\mathrm{y}=$ lokasi piksel baru vartikal

$\mathrm{Q}_{11}=$ kuartil atas

$\mathrm{Q}_{22}=$ kuartil bawah

b. Interpolasi Linier

Bentuk interpolasi yang paling mudah adalah menghubungkan dua buah titik data dengan sebuah garis lurus. Teknik ini dan sebagainya interpolasi linier dan dilukiskan secara grafis, dengan rumus sebagai berikut : 


$$
f(x)=f(x)+\frac{f\left(x_{1}\right)}{x_{1}-\mathrm{x}_{0}}\left(\mathrm{x}-\mathrm{x}_{0}\right)
$$

Keterangan :

$$
\begin{array}{ll}
\mathrm{f}(\mathrm{x}) & =\text { intesitas warna RGB titik yang dicari } \\
\mathrm{f}\left(\mathrm{x}_{0}\right) & =\text { intesitas warna RGB titik sebelah kiri } \\
\mathrm{f}\left(\mathrm{x}_{1}\right) & =\text { intesitas warna RGB titik sebelah kanan } \\
\mathrm{x}_{0} & =\text { posisi titik sebelah kiri } \\
\mathrm{x}_{1} & =\text { posisi sebelah kanan } \\
\mathrm{x} & =\text { titik yang dicari }
\end{array}
$$

3. Rekontruksi

Proses ini lakukan dengan menggunakan metode median filter. Median filter dicari dengan melakukan pengurutan terhadap nilai piksel dari mask yang sudah ditentukan, kemudan dicari nilai tengahnya. Fajar Astuti Hermawati (2013), filter ini mengganti nilai piksel dengan nilai median dari gray-level dalam subimage dibawah jendela ketetanggaan ukuran $\mathrm{m} \times \mathrm{n}$, sebagaimana persamaan berikut :

$$
\begin{aligned}
& f(x, y)=\operatorname{median}\{\mathrm{g}(\mathrm{s}, \mathrm{t})\} \\
& x(s, t) \in S_{x y}
\end{aligned}
$$

\section{HASIL DAN PEMBAHASAN}

Gambar yang dianalisa adalah gambar screenshot yang dimana gambar tersebut diambil melalui laptop kemudian akan diproses untuk meningkatkan kualitas citra. Proses awal peningkatan kualitas citra hasil gambar screenshot dengan metode super resolusi ini adalah melakukan penyeleksian gambar screenshot yang diambil dari layar monitor laptop, setelah gambar screenshot didapatkan, maka dilakukan cropping untuk mendapatkan gambar yang kurang baik, setelah dilakukan cropping maka disimpan gambar dengan format JPEG. Setelah hasil penyeleksian hasil gambar screenshot di dapatkan proses selanjutnya adalah membaca resolusi citra masukan yang berupa JPG objek yang berguna untuk mengetahui ukuran atau resolusi citra tersebut. Proses pembesaran citra dilakukan didalam objek JPG dan resolusi akan bertambah setelah proses pembesaran dilakukan pada gambar masukan. proses penambahan pixel atau titik baru ini dilakukan dengan menyisipkan titik-titik tersebut diantara titik-titik yang harganya telah tetap yang dipetakan langsung dari citra asli.

Sebuah citra hasil screenshot yang berformat JPG yang ingin ditingkatkan kualitas citra dengan metode super resolusi, proses ini dilakukan dengan tahap registrasi average, interpolasi linier untuk pembesaran dan tahap median filter untuk penghalusan. Citra input gambar screenshot yang digunakan untuk memahami proses penyelesaian metode super resolusi adalah sebagai berikut :

1. Melakukan screenshot dari objek gambar layar monitor dengan cara menekan tombol PrtScsyrq

2. Menyeleksi gambar screenshot

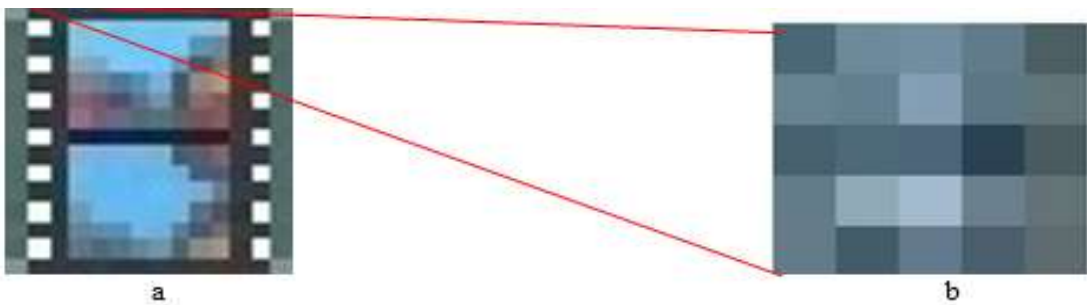

3. Nilai Pixel

Gambar 1. a) Hasil Screenshot 50x53 dan b) Sample citra nilai pixel 5x5

Tabel 1. Nilai Pixel Grayscale

\begin{tabular}{|c|c|c|c|c|}
\hline 96 & 113 & 135 & 117 & 90 \\
\hline 124 & 120 & 153 & 112 & 111 \\
\hline 91 & 99 & 96 & 61 & 87 \\
\hline 118 & 164 & 182 & 123 & 111 \\
\hline 118 & 86 & 117 & 90 & 103 \\
\hline
\end{tabular}

\subsection{Penerapan Metode Super Resolusi Pada Citra Hasil Screenshot}

Teknik super resolusi terdiri dari tiga tahap yaitu Registrasi, interpolasi dan rekrontruksi. Pada tahap regristrasi menggunakan Registrasi Average yang melakukan pecarian nilai rata-rata piksel dari beberapa frame citra yang mengalami transformasi geomatri, kemudian membaginya dengan banyak frame citra. Teknik citra super resolusi adalah salah satu teknik untuk mendapatkan citra yang beresolusi tinggi dari sekumpulan citra yang beresolusi rendah. Resolusi tinggi yang dihasilkan dapat berupa citra tunggal atau lebih.

Super resolusi secara umum terdiri dari tiga tahap algoritma yaitu :

1. Registrasi 
Persamaan nilai rata-rata piksel dapat ditunjukkan sebagi berikut.

Tabel 2. Nilai Pixel 5x5

\begin{tabular}{|c|c|c|c|c|}
\hline 96 & 113 & 135 & 117 & 90 \\
\hline 124 & 120 & 153 & 112 & 111 \\
\hline 91 & 99 & 96 & 61 & 87 \\
\hline 118 & 164 & 182 & 123 & 111 \\
\hline 118 & 86 & 117 & 90 & 103 \\
\hline
\end{tabular}

1. Nilai piksel dilakukan kernel matriks $3 \times 3$ proses perhitungannya adalah sebagai berikut :

\begin{tabular}{|l|l|l|}
\hline 96 & 113 & 135 \\
\hline 124 & 120 & 153 \\
\hline 91 & 99 & 96 \\
\hline
\end{tabular}

$$
\begin{aligned}
f(x, y) & =\frac{x_{1}+x_{2}+x_{3}+x_{4}+x_{5}+x_{6}+x_{7}+x_{8}+x_{9}}{n} \\
& =\frac{96+113+135+124+120+153+91+99+96}{9} \\
& =\frac{1.027}{9} \\
& =114
\end{aligned}
$$

Hasil pada tahap Regristrasi Average adalah x (114), sehingga nilai 120 diganti menjadi 114, ditempatkan menjadi matriks yang baru, hasilnya dapat dilihat sebagai berikut :

\begin{tabular}{|l|l|l|}
\hline 96 & 113 & 135 \\
\hline 124 & 120 & 153 \\
\hline 91 & 99 & 96 \\
& & \\
\hline
\end{tabular}

Sehingga dilakukan proses Registrasi Average dengan menggunakan kernel 3x3 sehingga menjadi citra yang baru. Dapat dilihat pada gambar dibawah ini.

\begin{tabular}{|c|c|c|c|c|}
\hline 96 & 113 & 135 & 117 & 90 \\
\hline 124 & 120 & 153 & 112 & 111 \\
\hline 91 & 99 & 96 & 61 & 87 \\
\hline 118 & 164 & 182 & 123 & 111 \\
\hline 118 & 86 & 117 & 90 & 103 \\
\hline
\end{tabular}

\section{Regristrasi Averag}

\begin{tabular}{|c|c|c|c|c|}
\hline 96 & 113 & 135 & 117 & 90 \\
\hline 124 & 114 & 118 & 106 & 111 \\
\hline 91 & 106 & 123 & 115 & 87 \\
\hline 118 & 106 & 113 & 108 & 111 \\
\hline 118 & 86 & 117 & 90 & 103 \\
\hline
\end{tabular}

\section{Interpolasi Linier}

Adapun langkah-langkah tahap interpolasi linier untuk pembesaran dapat dilakukan sebagai berikut :

a. Citra pembesaran 5x5 pixel dengan tahap interpolasi linier yang akan diterapkan kedalam metode super resolusi

Tabel 3. Nilai Pixel 5x5

\begin{tabular}{|c|c|c|c|c|}
\hline 96 & 113 & 135 & 117 & 90 \\
\hline 124 & 114 & 118 & 106 & 111 \\
\hline 91 & 106 & 123 & 115 & 87 \\
\hline 118 & 106 & 113 & 108 & 111 \\
\hline 118 & 86 & 117 & 90 & 103 \\
\hline
\end{tabular}

b. Mencari nilai height dan new width

Penyelesaian :

New height $=$ tinggi pixel yang dicari

New width $=$ lebar pixel yang dicari

Old height $=$ tinggi pixel sebelumnya

Old width = lebar sebelumnya

Scale $=$ pembesaran yang dilakukan 
New height $=($ Old height $*$ Scale $)$

$=5 * 2$

$=10$

New width $=($ Old width $*$ Scale $)$

$=5 * 2$

$=10$

c. Pembentukan Pembesaran Matrik.

Maka hasil height dan width adalah 10x10, sedangkan untuk memetakan intensitas warna RGB yang ada pada citra asli ke warna citra pada new JPEG, untuk pixel dengan posisi 0 maka, pixel terakhir (height-1) atau (width-1) akan dipetakan ke posisi yang sama pada new JPEG, hal ini penting agar tidak terjadi pixel sisa yang tidak berguna atau menyebabkan kerusakan gambar. Sehingga nilai hasil height dan width adalah 9x9 dan memiliki nilai matriknya adalah sebagai berikut :

Tabel 4. Nilai Matrik Pembesaran Citra

\begin{tabular}{|c|l|l|l|l|l|l|l|l|}
\hline 96 & & 113 & & 135 & & 117 & & 90 \\
\hline & & & & & & & & \\
\hline 124 & & 114 & & 118 & & 106 & & 111 \\
\hline 91 & & 106 & & 123 & & 115 & & 87 \\
\hline & & & & & & & & \\
\hline 118 & & 106 & & 113 & & 108 & & 111 \\
\hline & & & & & & & & \\
\hline 118 & & 84 & & 117 & & 90 & & 103 \\
\hline
\end{tabular}

d. Proses mencari nilai pixel yang kosong dengan tahap interpolasi linier

Nilai Interpolasi Linier $=$

$$
\begin{aligned}
& f(x)=f\left(x_{0}\right)+\frac{f\left(x_{1}\right)-f\left(x_{0}\right)}{x_{1}-x_{0}} X_{1}-X_{0} \\
& =96+\frac{113-96}{113-96} 113-96 \\
& =96+17 \\
& =113
\end{aligned}
$$

\begin{tabular}{|l|l|l|}
\hline 96 & & 113 \\
\hline & & \\
\hline 124 & & 114 \\
\hline
\end{tabular}

Interpolasi linier

\begin{tabular}{|l|l|l|}
\hline 96 & 113 & 113 \\
\hline & & \\
\hline 124 & & 114 \\
\hline
\end{tabular}

Hasil matrik pembesaran sehingga menjadi citra yang baru. Dapat dilihat pada dibawah ini adalah sebagai berikut :

Tabel 5. Matrik pembesaran citra

\begin{tabular}{|l|l|l|l|l|l|l|l|l|l|}
\hline 96 & 113 & 113 & 135 & 135 & 117 & 117 & 90 & 90 & 0 \\
\hline 124 & 114 & 114 & 118 & 118 & 106 & 106 & 111 & 111 & 0 \\
\hline 124 & 114 & 114 & 118 & 118 & 106 & 106 & 111 & 111 & 0 \\
\hline 91 & 114 & 106 & 123 & 123 & 115 & 115 & 87 & 87 & 0 \\
\hline 91 & 106 & 106 & 123 & 123 & 115 & 115 & 87 & 87 & 0 \\
\hline 118 & 106 & 106 & 113 & 113 & 108 & 108 & 111 & 111 & 0 \\
\hline 118 & 106 & 106 & 113 & 113 & 108 & 108 & 111 & 111 & 0 \\
\hline 118 & 86 & 86 & 117 & 117 & 90 & 90 & 103 & 103 & 0 \\
\hline 118 & 86 & 86 & 117 & 117 & 90 & 90 & 103 & 103 & 0 \\
\hline 0 & 0 & 0 & 0 & 0 & 0 & 0 & 0 & 0 & 0 \\
\hline
\end{tabular}

3. Rekontruksi 
Proses ini dilakukan dengan menggunakan metode median filter. Median filter dicari dengan melakukan pengurutan terhadap nilai piksel dari mask yang sudah ditentukan, kemudian dicari nilai tengahnya. Adapun langkah-langkah untuk median filter sebagai berikut :

Tabel 6. Citra Input

\begin{tabular}{|l|l|l|l|l|l|l|l|l|l|}
\hline 96 & 113 & 113 & 135 & 135 & 117 & 117 & 90 & 90 & 0 \\
\hline 124 & 114 & 114 & 118 & 118 & 106 & 106 & 111 & 111 & 0 \\
\hline 124 & 114 & 114 & 118 & 118 & 106 & 106 & 111 & 111 & 0 \\
\hline 91 & 114 & 106 & 123 & 123 & 115 & 115 & 87 & 87 & 0 \\
\hline 91 & 106 & 106 & 123 & 123 & 115 & 115 & 87 & 87 & 0 \\
\hline 118 & 106 & 106 & 113 & 113 & 108 & 108 & 111 & 111 & 0 \\
\hline 118 & 106 & 106 & 113 & 113 & 108 & 108 & 111 & 111 & 0 \\
\hline 118 & 86 & 86 & 117 & 117 & 90 & 90 & 103 & 103 & 0 \\
\hline 118 & 86 & 86 & 117 & 117 & 90 & 90 & 103 & 103 & 0 \\
\hline 0 & 0 & 0 & 0 & 0 & 0 & 0 & 0 & 0 & 0 \\
\hline
\end{tabular}

$f(x, y)=\operatorname{median}\{g(s, t)\}$

$(s, t) \in S x y$

$\mathrm{f}(1,2)=$\begin{tabular}{|l|l|l|}
\hline 96 & 113 & 113 \\
\hline 124 & 114 & 114 \\
\hline 124 & 114 & 114 \\
\hline
\end{tabular}

$\mathrm{f}(1,2)=\begin{array}{lllllllll}96 & 113 & 113 & 114 & 114 & 114 & 114 & 124 & 124\end{array}$

$\mathrm{f}(1,2)=114$

Selanjutnya menggeser kolom berikut dengan kernel 3x3 dan kemudian dicari nilai tengahnya dengan tahap Rekontruksi menggunakan metode median filter dari piksel-piksel berikutnya. Setelah dilakukan proses rekontruksi menggunakan median filter dengan kernel 9x9 sehingga menjadi hasil citra yang baru. dari pengujian yang dilakukan metode mendian filter dapat memperhalus kualitas citra

Tabel 7. Hasil Rekontruksi pembesaran citra

\begin{tabular}{|l|l|l|l|l|l|l|l|l|}
\hline 96 & 113 & 113 & 135 & 135 & 117 & 117 & 90 & 90 \\
\hline 124 & 114 & 114 & 118 & 118 & 117 & 106 & 111 & 111 \\
\hline 124 & 114 & 114 & 118 & 118 & 115 & 106 & 111 & 111 \\
\hline 91 & 114 & 114 & 118 & 118 & 115 & 111 & 106 & 87 \\
\hline 91 & 106 & 106 & 113 & 115 & 115 & 111 & 108 & 87 \\
\hline 118 & 106 & 106 & 113 & 113 & 113 & 108 & 111 & 111 \\
\hline 118 & 106 & 106 & 113 & 113 & 108 & 108 & 108 & 111 \\
\hline 118 & 106 & 106 & 113 & 113 & 108 & 103 & 103 & 103 \\
\hline 118 & 86 & 86 & 117 & 117 & 90 & 90 & 103 & 103 \\
\hline
\end{tabular}

Berdasarkan data hasil pembesaran citra hasil Screenshot menunjukkan bahwa resolusi yang dihasilkan oleh citra hasil pembesaran berbeda. Resolusi citra hasil Screenshot sama sehingga resolusi citra hasil pembesaran akan berbeda. Kecepatan aplikasi untuk melakukan proses pembesaran citra tersebut tidak tergantung kepada resolusi spasial citra, tetapi lama proses pembesaran citra tergantung pada resolusi pixsel dan juga tergantung pada spesifikasi komputer yang menjalankan aplikasi pembesaran citra tersebut

\section{KESIMPULAN}

Dari hasil penelitia ini, maka dapat diambil kesimpulan, sebagai berikut :

1. Proses meningkatkan kualitas pada citra hasil screenshot dilakukan dengan cara pembesaran dengan menerapkan metode super resolusi yang menyangkut variasi ukuran piksel sehingga dapat diukur kecepatan waktu proses dan tingkat keberhasilannya.

3. Aplikasi pembesaran citra hasil screenshot telah selesai dirancang dengan menggunakan matlab R2013a dan dapat dijalankan pada sistem operasi windows.

3. Metode super resolusi dapat diterapkan dalam meningkatkan kualitas pada citra hasil screenshot dengan cara pembesaran citra. Aplikasi pembesaran citra telah dapat meningkatkan resolusi spasial citra sehingga dapat memudahkan pengguna melakukan pembesaran citra untuk meningkatkan resolusi spasialnya.

\section{REFERENCES}


[1] N. S. Soeb Aripin, Guidio Leonarde Ginting, "Penerapan metode retinex untuk meningkatkan kecerahan citra pada hasil screenshot," vol. 1, no. 1, pp. 24-27, 2017.

[2] N. M. Abdi and S. Aisyah, "Peningkatan Kualitas Citra Digital Menggunakan Metode Super Resolusi Pada Domain Spasial," vol. 9, no. 3, pp. 137-142, 2011.

[3] S. Aripin and H. Sunandar, "Perancangan Aplikasi Perbaikan Citra Pada Hasil Screenshot Menggunakan Metode Interpolasi Linier," vol. 15 , no. 1,2016

[4] M. K. T.sutoyo, S.Si., M.Kom., Edy Muyanto, S.Si., M.Kom., Dr. Vincent Suhartono, Oky Dwi Nurhayati, M.T., Wijanarto, Pengolahan Citra Digital, Andi. Yogyakarta, 2009.

[5] D. Putra, Pengolahan Citra Digital, Andi. Yogyakarta, 2010.

[6] A. K. \& A. Susanto, Teori dan Aplikasi Pengolahan citra, Andi. Yogyakarta, 2013.

[7] R. Astuti, "PENERAPAN METODE INTERPOLASI LINIER DAN METODE SUPER RESOLUSI PADA PEMBESARAN CITRA," vol. 1, no. 2, pp. 161-169, 2016.

[8] R. A. S.M . Shalahuddin, Rekayasa Perangkat Lunak, Informatik. Bandung, 2014.

[9] W. Komputer, Ragam Aplikasi Pengolahan Image dengan Matlab, PT Elex Me. Jakarta. 